\title{
Effect of cooling rate and composition on microstructure and mechanical properties of ultrahigh-strength steels
}

\author{
Mohammed Ali ${ }^{1,2}$ (D) $\cdot$ David Porter ${ }^{1} \cdot$ Jukka Kömi $^{1} \cdot$ Mamdouh Eissa $^{2} \cdot$ Hoda El Faramawy $^{2} \cdot$ Taha Mattar $^{2}$
}

Received: 23 October 2018/Revised: 13 December 2018/Accepted: 25 December 2018/Published online: 16 May 2019

(C) The Author(s) 2019

\begin{abstract}
The influence of cooling rate on the microstructure and mechanical properties of two new ultrahigh-strength steels (UHSSs) with different levels of $\mathrm{C}, \mathrm{Cr}$ and $\mathrm{Ni}$ has been evaluated for the as-cooled and untempered condition. One UHSS had higher contents of $\mathrm{C}$ and $\mathrm{Cr}$, while the other one had a higher $\mathrm{Ni}$ content. On the basis of dilatation curves, microstructures, macrohardness and microhardness, continuous cooling transformation diagrams were constructed as a guide to heat treatment possibilities. Cooling rates (CRs) of 60,1 and $0.01{ }^{\circ} \mathrm{C} / \mathrm{s}$ were selected for more detailed investigations. Microstructural characterization was made by laser scanning confocal microscopy, field emission scanning electron microscopy combined with electron backscatter diffraction, electron probe microanalysis and X-ray diffraction. Mechanical properties were characterized using macrohardness, tensile and Charpy V-notch impact tests. UHSS with the higher $\mathrm{C}$ and $\mathrm{Cr}$ contents showed lower transformation temperatures and slower bainite formation kinetics than that with the higher Ni content. Higher cooling rates led to lower volume fractions and carbon contents of retained austenite together with finer prior austenite grain size, as well as effective final grain size and lath size. These changes were accompanied by higher yield and tensile strengths. The best combinations of strength and toughness were obtained with martensitic microstructures and by avoiding the formation of granular bainite accompanied by proeutectoid carbides at low CR. For the cooling rates studied, UHSS with the higher $\mathrm{C}$ and $\mathrm{Cr}$ contents showed the higher hardness and strength but at the cost of toughness.
\end{abstract}

Keywords Ultrahigh-strength steel · Electroslag remelting · Continuous cooling transformation diagram ·

Microstructure feature $\cdot$ Mechanical property

\section{Introduction}

Nowadays, ultrahigh-strength steels (UHSSs) are widely used in many applications such as automotive, locomotive and truck components, pressure vessels, offshore platforms, engineering machinery, the mining, military and aerospace industry, due to their good combinations of strength, toughness and ductility [1-5].

Mohammed Ali

mohammed.ali@oulu.fi; mohammedsalah2020@gmail.com

1 Materials and Mechanical Engineering, Centre for Advanced Steels Research, University of Oulu, Oulu 90014, Finland

2 Steel Technology Department, Central Metallurgical Research and Development Institute, Helwan, Cairo 11421, Egypt
Recently, different grades of steels have been developed as potential replacements for the high-cost ultrahighstrength steels containing high levels of $\mathrm{Co}$ and Ni such as AerMet100, HP 9-4-20, HP 9-4-30 and AF1410 to attain substantially reduced costs and processing time. Based on a medium-carbon V-microalloyed composition alloyed with moderate levels of $\mathrm{Si}, \mathrm{Ni}, \mathrm{Cr}, \mathrm{Mo}$ and $\mathrm{W}$, Dilmore and Ruhlman [6] developed the ultrahigh-strength Eglin steel that, after tempering at $260{ }^{\circ} \mathrm{C}$, achieves a hardness of 458 $\mathrm{HV}$, an ultimate tensile strength of $1685 \mathrm{MPa}$, a yield strength of $1392 \mathrm{MPa}$, elongation to fracture of $17.5 \%$ and a Charpy V-notch impact toughness of $37 \mathrm{~J}$ at room temperature. With the aim of improving the strength-toughness balance achievable with Eglin steel, especially in thicker sections with low cooling rates (CRs), Vartanov [7] designed a medium-carbon steel microalloyed with $\mathrm{V}$ in combination with $\mathrm{Nb}$ or $\mathrm{Ti}$ but less $\mathrm{Ni}$ and $\mathrm{W}$ than that in 
the Eglin steel. After tempering at $216{ }^{\circ} \mathrm{C}$, the designed steel obtains a hardness of $594 \mathrm{HV}$, an ultimate tensile strength of $2055 \mathrm{MPa}$, a yield strength of $1578 \mathrm{MPa}$, an elongation to fracture of $13.5 \%$ and a room-temperature Charpy V-notch impact toughness of $35 \mathrm{~J}$.

The main difference between the currently investigated steels is in $\mathrm{C}, \mathrm{Cr}$ and $\mathrm{Ni}$ contents. $\mathrm{C}$ is the most important element used to increase hardness and strength through (i) lowering of the phase transformation temperatures during continuous cooling, thereby refining the microstructure and increasing the dislocation density, (ii) an increase in solid solution strengthening, and (iii) carbide precipitation strengthening [8]. However, the level of carbon alloying needs to be limited to avoid detrimental effects on weldability and toughness. $\mathrm{Cr}$ is used to enhance strength and hardenability through transformation strengthening and, when it is combined with $\mathrm{C}$, it is a powerful hardening alloy element. Also, it increases corrosion resistance. Ni has a positive influence on toughness and also helps to stabilize retained austenite (RA).

The present work has been undertaken in order to extend the studies of Dilmore and Ruhlman [6] by exploring the possibilities of producing ultrahigh-strength tough steel with even lower cost via the use of recycled steels, ferroalloys and nickel alloys through air melting and electroslag remelting applied to two low-purity Eglin steels with traces of $\mathrm{Ti}$ and $\mathrm{Nb}$ as described in previous publication [9]. The use of simpler liquid steel treatment means that the impurity and inclusion contents are higher than those obtained with vacuum treatments $[9,10]$. In the present paper, we explore the phase transformations, together with the resultant microstructure and mechanical properties of the current lower-purity Eglin steels with traces of $\mathrm{Ti}$ and $\mathrm{Nb}$ for the wide range of cooling rates that can be encountered in practical processing. Mechanical properties are investigated using tensile, hardness and Charpy V-notch (CVN) impact testing. Microstructures are characterized with regard to the fractions of martensite, bainite and retained austenite together with the sizes of prior austenite grains and the sizes of grains defined by low-angle and high-angle grain boundaries.

\section{Experimental}

Two experimental heats with the chemical compositions given in Table 1 were designed, melted using an induction furnace and cast into ingots of $70 \mathrm{~mm}$ in diameter in the Steel Technology Department, Central Metallurgical Research and Development Institute (CMRDI), Egypt. For each steel, after discarding $30 \mathrm{~mm}$ from the bottom, the cast ingots were cut into two equal lengths and they were subsequently reheated to $1100{ }^{\circ} \mathrm{C}$ and held for $1 \mathrm{~h}$ followed by forging in the temperature range of $950-1100{ }^{\circ} \mathrm{C}$ to a bar with a cross section of $28 \mathrm{~mm} \times 30$ $\mathrm{mm}$, which was then air-cooled with an average cooling rate of $0.3{ }^{\circ} \mathrm{C} / \mathrm{s}$ over the temperature range of $950-35^{\circ} \mathrm{C}$. For each steel, one of the forged bars was used as a consumable electrode for electroslag remelting (ESR) under a synthetic fused slag containing about $70 \% \mathrm{CaF}_{2}, 15 \% \mathrm{Al}_{2} \mathrm{O}_{3}$ and $15 \% \mathrm{CaO}$ in weight percentage. The 70-mm-diameter ESR ingot was subsequently forged and cooled using the same parameters that were used for the base ingot from the induction furnace.

Continuous cooling transformation (CCT) diagrams of the investigated steels were produced using dilatation experiments on a Gleeble 3800 thermomechanical simulator with cylindrical samples of $6 \mathrm{~mm}$ in diameter and length of $20 \mathrm{~mm}$ machined with the cylindrical axis parallel to the forging direction. The critical transformation temperatures $A_{\mathrm{c} 1}$ and $A_{\mathrm{c} 3}$ were determined using the tangent method on dilatation curves produced during heating at $5{ }^{\circ} \mathrm{C} / \mathrm{s}$. The transformation temperatures on cooling were determined using the tangent method on the dilatation curves obtained after heating the samples at $5{ }^{\circ} \mathrm{C} / \mathrm{s}$ to $1100{ }^{\circ} \mathrm{C}$, holding for $3 \mathrm{~min}$, cooling to $950{ }^{\circ} \mathrm{C}$ at $2{ }^{\circ} \mathrm{C} / \mathrm{s}$, holding for $3 \mathrm{~min}$ and finally cooling to room temperature at linear cooling rates ranging from 0.01 to $60^{\circ} \mathrm{C} / \mathrm{s}$ as illustrated in Fig. 1.

A laser scanning confocal microscope (LSCM) was used to investigate all samples after phase transformation. Samples were cut, mounted, ground, polished down to $1 \mu \mathrm{m}$ using a diamond suspension and then ultrasonically cleaned. All samples were etched using 4 vol.\% picric acid for 30-60 s followed by fresh 2 vol.\% Nital solution for 30-60 s. After each step, samples were washed with water and ethanol and then dried in air. In order to identify martensitic and bainitic regions for the determination of microhardness, tint etching was used. The samples were first etched using 4 vol.\% picric acid for $1 \mathrm{~min}$ and then etched for 15-20 s using a 10\% aqueous solution of sodium metabisulfite ( $10 \mathrm{~g}$ of $\mathrm{Na}_{2} \mathrm{~S}_{2} \mathrm{O}_{5}$ in $100 \mathrm{~mL}$ distilled water). The samples were oscillated strongly during the whole etching process. After each step, the surface of the sample was cleaned using water and ethanol followed by drying [11].

Microhardness tests were performed on a CSM microindentation tester using a maximum load of $0.25 \mathrm{~N}$, a loading rate of $0.50 \mathrm{~N} / \mathrm{min}$, an unloading rate of $0.50 \mathrm{~N} /$ min and a pause time of $10 \mathrm{~s}$. At least 15 random measurements across the samples were used to determine characteristic average values. CCT diagrams were constructed based on the results from dilatation curves, final microstructures and microhardness values. HV10 macrohardness measurements were made using a Duramin-A300 (Struers) macrohardness tester at 10 random positions 
Table 1 Chemical composition of investigated UHSSs (wt.\%)

\begin{tabular}{lllllllllllllllllll}
\hline Steel & $\mathrm{C}$ & $\mathrm{Cr}$ & $\mathrm{Ni}$ & $\mathrm{Mo}$ & $\mathrm{W}$ & $\mathrm{Mn}$ & $\mathrm{Si}$ & $\mathrm{V}$ & $\mathrm{Ti}$ & $\mathrm{Nb}$ & $\mathrm{Cu}$ & $\mathrm{Al}$ & $\mathrm{P}$ & $\mathrm{S}$ & $\mathrm{N}$ & $\mathrm{O}$ & $\mathrm{Fe}$ \\
\hline UHSS A & 0.320 & 2.18 & 2.31 & 0.31 & 1.14 & 0.64 & 0.64 & 0.072 & 0.001 & 0.001 & 0.020 & 0.060 & 0.018 & 0.013 & 0.011 & 0.004 & Balance \\
UHSS B & 0.305 & 1.57 & 3.13 & 0.30 & 1.26 & 0.57 & 0.65 & 0.072 & 0.002 & 0.002 & 0.013 & 0.043 & 0.020 & 0.012 & 0.016 & 0.013 & Balance \\
\hline
\end{tabular}

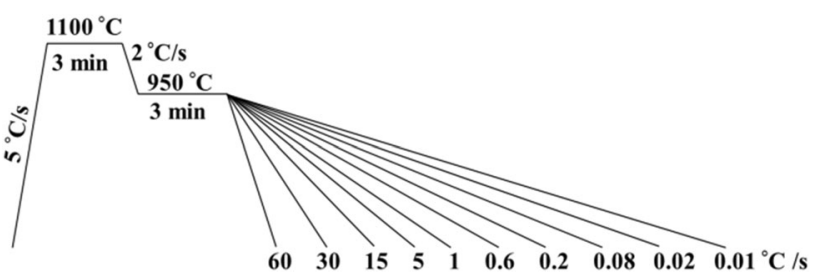

Fig. 1 Gleeble simulation procedures for constructing CCT diagrams

across the samples used for the microstructure investigations after repolishing.

The thermal cycles in Fig. 1 with cooling rates of 60,1 and $0.01{ }^{\circ} \mathrm{C} / \mathrm{s}$ were selected for more detailed studies of the effect of the cooling rate on the microstructures and mechanical properties. Using the Gleeble thermomechanical simulator, samples with the dimensions of $\phi 6 \mathrm{~mm} \times$ $90 \mathrm{~mm}$ were thermally cycled on using a free span of $20 \mathrm{~mm}$ which gave a uniform microstructure and hardness over a distance of $15 \mathrm{~mm}$ in the middle of the free span. Samples were subsequently machined to round tensile samples with a diameter of $(4 \pm 0.1) \mathrm{mm}$ and a gauge length of (16 \pm 0.1$) \mathrm{mm}$ according to ASTM standard E8. Tensile testing was done using a Zwick/Roell machine with a maximum load capacity of $100 \mathrm{kN}$. CVN impact test samples were thermally cycled using the Gleeble thermomechanical simulator with free span of $5 \mathrm{~mm}$ which gave uniform microstructure and hardness over $5 \mathrm{~mm}$ in the middle of the samples, and then the notch was machined in the middle of the samples at the location of the control thermocouple. Impact tests were performed at room temperature $\left(20{ }^{\circ} \mathrm{C}\right)$ and $-40{ }^{\circ} \mathrm{C}$ according to ASTM E 23-05 on standard sub-sized CVN impact samples $(5 \mathrm{~mm} \times 10$ $\mathrm{mm} \times 55 \mathrm{~mm}$ ) using a calibrated Charpy impact test hammer with a capacity of $350 \mathrm{~J}$. The results are average values of three samples. The thermal cycle for the tensile and impact samples with a cooling rate of $0.01{ }^{\circ} \mathrm{C} / \mathrm{s}$ was performed in a controllable furnace and left in the furnace for cooling with an average cooling rate of $0.01{ }^{\circ} \mathrm{C} / \mathrm{s}$.

The microstructures of the samples used for the macrohardness tests were also characterized using a field emission scanning electron microscope (FESEM, Zeiss Sigma). Average effective grain size and grain boundary misorientation distributions were measured using an energy-dispersive X-ray (EDAX) electron backscatter diffraction (EBSD) system on FESEM with an accelerating voltage of $15 \mathrm{kV}$, a magnification of 2000 and a step size of $0.15 \mu \mathrm{m}$. Grain boundaries with misorientation higher than $2^{\circ}$ and higher than $15^{\circ}$ were considered as lath boundaries and high-angle grain boundaries, respectively [12, 13]. High-angle grain boundaries refer to the boundaries of blocks or packets [14, 15]. Equivalent circular diameter (ECD) was used to define the lath size and the effective grain size as defined by the high-angle grain boundaries. For EBSD examination, the sample surface was first polished with a diamond suspension down to $1 \mu \mathrm{m}$ and then chemically polished using a $0.05-\mu \mathrm{m}$ colloidal silica suspension. To determine the prior austenite grain size, different EBSD runs were performed at low magnification with an accelerating voltage of $15 \mathrm{kV}$, a magnification of 500 and a step size of $0.65 \mu \mathrm{m}$. To reveal prior austenite grain (PAG) structure, EBSD orientation data were used to reconstruct the prior austenite using MATLAB software combined with the MTEX texture and crystallographic analysis toolbox [16-18]. The linear intercept method was then used to determine prior austenite grain size (PAGS) from the reconstructed image.

The volume fraction of retained austenite was determined using a Rigaku SmartLab X-ray diffractometer with $\mathrm{Co} \mathrm{K} \alpha$ radiation under the following conditions: accelerating voltage of $40 \mathrm{kV}$, current of $135 \mathrm{~mA}$, scanning speed of $1.0039\left(^{\circ}\right) / \mathrm{min}$, step size of $0.05^{\circ}$ and range of $40^{\circ}>2 \theta>130^{\circ}$. Samples from the fractured sub-sized CVN impact samples with the dimensions of $10 \mathrm{~mm} \times$ $10 \mathrm{~mm} \times 5 \mathrm{~mm}$ were cut, ground, polished using a diamond suspension down to $1 \mu \mathrm{m}$ and then ultrasonically cleaned in ethanol to remove any dust or particles on the surface. To determine the volume fractions of austenite, $\mathrm{X}$-ray diffraction data were treated using the whole profile Rietveld refinement analysis using PDXL2 analysis software. The carbon content of the retained austenite $\left(C_{\gamma}\right)$ was estimated from the lattice parameter, i.e., $a=0.3578+$ $0.0033 C_{\gamma}$ [19], where $a$ is the lattice parameter of the retained austenite, $\mathrm{nm}$.

To determine the chemical constituents in grain boundary carbides, Jeol JXA-8200 electron probe microanalysis (EPMA) using line scan analyses with a step size of $0.4 \mu \mathrm{m}$ was made in the case of samples cooled at $0.01{ }^{\circ} \mathrm{C} / \mathrm{s}$. Samples for EPMA were prepared by repolishing the microstructural samples and lightly etching using 4 vol. $\%$ picric acid for $20 \mathrm{~s}$ followed by fresh 2 vol.\% 
Nital solution for $20 \mathrm{~s}$. The results from EPMA were confirmed using FESEM energy-dispersive X-ray spectroscope (EDS) analysis of the carbides formed at the PAG boundaries using the same samples.

\section{Results and discussion}

\subsection{CCT diagrams}

The values of $A_{\mathrm{c} 1}$ and $A_{\mathrm{c} 3}$ for UHSS A are 746 and $831{ }^{\circ} \mathrm{C}$, and those for UHSS B are 734 and $845{ }^{\circ} \mathrm{C}$, respectively. CCT diagrams based on dilatation curves, LSCM micrographs, macrohardness and microhardness values are shown in Fig. 2. $M_{\mathrm{s}}$ and $M_{\mathrm{f}}$ are the martensite start and finish transformation temperatures. $B_{\mathrm{s}}$ and $B_{\mathrm{f}}$ are the bainite start and finish transformation temperatures. The effect of $\mathrm{C}$ content and $\mathrm{Cr} / \mathrm{Ni}$ ratio is clearly observed from Fig. 2: $A_{\mathrm{c} 1}$ increased as a result of increasing $\mathrm{Cr} / \mathrm{Ni}$ ratio and a small increase in $\mathrm{C}$ content, while $A_{\mathrm{c} 3}, M_{\mathrm{s}}$ and $B_{\mathrm{s}}$ decreased. Typical LSCM micrographs after phase transformation at different cooling rates are shown in Figs. 3 and 4. The higher hardness values of UHSS A (635-416 HV) compared to those of UHSS B (580-393 HV) result from the higher hardenability provided by the higher $\mathrm{C}$ content and $\mathrm{Cr} / \mathrm{Ni}$ ratio. This results in lower transformation temperatures and thereby finer microstructures and higher dislocation densities. The microhardness values of the transformation products are given in Fig. 5. In UHSS A, martensite with hardness ranging from 635 to $570 \mathrm{HV}$ was obtained over the wide range of cooling rates from 60 to $0.2{ }^{\circ} \mathrm{C} / \mathrm{s}$ and a mixture microstructure of martensite and bainite was obtained from 0.08 to $0.02{ }^{\circ} \mathrm{C} / \mathrm{s}$ with hardness range from 543 to $430 \mathrm{HV}$. However, the main transformation product at $0.01{ }^{\circ} \mathrm{C} / \mathrm{s}$ with hardness of $416 \mathrm{HV}$ was

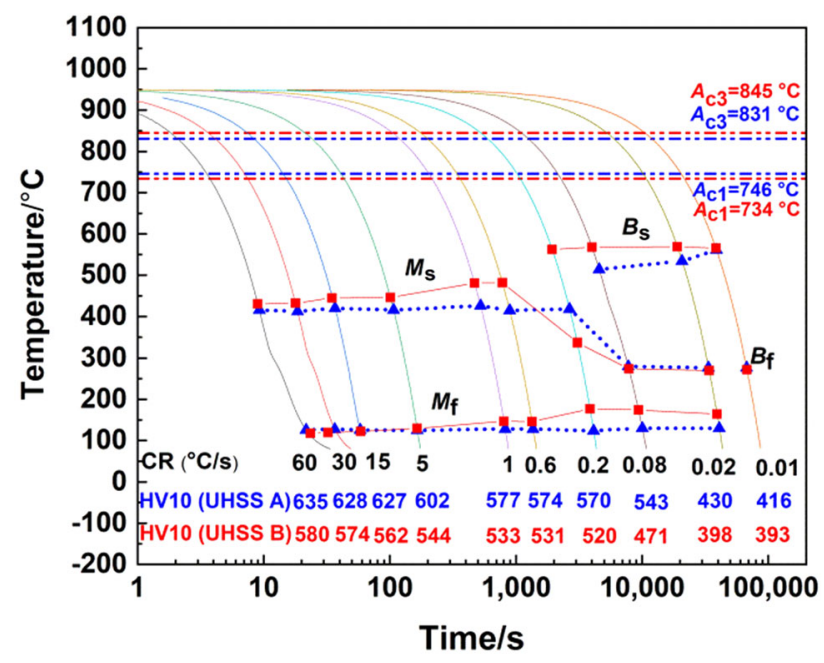

Fig. 2 CCT diagram for UHSS A and UHSS B granular bainite. Also, carbides were formed at the prior austenite grain boundaries as shown in Fig. 3j. The same transformation products were observed in UHSS B but with some difference as bainite started to form at the cooling rate of $0.2{ }^{\circ} \mathrm{C} / \mathrm{s}$ instead of $0.08{ }^{\circ} \mathrm{C} / \mathrm{s}$ in UHSS A due to its lower $\mathrm{C}$ content and $\mathrm{Cr} / \mathrm{Ni}$ ratio, which decrease the hardenability and shift the bainite transformation curve to a higher cooling rate.

In UHSS A, the microhardness of the martensite increased from the slowest cooling rates up to $15^{\circ} \mathrm{C} / \mathrm{s}$ after which the hardness is constant, see Fig. 5a. This behavior may be due to the increasing loss of carbon from the martensite laths into an increasing volume fraction of retained austenite as explained below [20]. Increasing the cooling rate from 0.01 to $0.08{ }^{\circ} \mathrm{C} / \mathrm{s}$ has no effect on the microhardness of the bainite as shown in Fig. 5a. The same trend of the microhardness of the martensite was observed for UHSS B (Fig. 5b). However, the microhardness of the bainite increased from 0.01 to $0.08{ }^{\circ} \mathrm{C} / \mathrm{s}$ and showed no further increase after this cooling rate. The clear difference in the microhardness of bainite over $\mathrm{CR}$ range from 0.01 to $0.08{ }^{\circ} \mathrm{C} / \mathrm{s}$ between the investigated steels can be explained by the formation of a large volume fraction of proeutectoid carbides at the slowest cooling rate in the case of UHSS A. This leads to an increasing consumption of $\mathrm{C}$ and other alloying elements like $\mathrm{W}, \mathrm{Mo}$ and $\mathrm{Cr}$ with decreasing CRs, which, in turn, leads to a drop in the hardness of the bainite. The effect can also be seen in the hardness of the martensite, too. The lower incidence of proeutectoid carbide in UHSS B seems to make this effect less apparent.

\subsection{Microstructure of UHSSs A and B}

SEM micrographs of UHSSs A and B with cooling rates of 60,1 and $0.01{ }^{\circ} \mathrm{C} / \mathrm{s}$ are shown in Fig. 6. They confirm the observations from LSCM and microhardness testing that the microstructure mainly consists of martensite at the cooling rates of 60 and $1{ }^{\circ} \mathrm{C} / \mathrm{s}$ and mainly granular bainite at the cooling rate of $0.01{ }^{\circ} \mathrm{C} / \mathrm{s}$. The large increase in PAGS as shown below and the slowest cooling rate enhance opportunity to form granular bainite which is characterized by the lack of carbides as shown in Fig. 6c, $\mathrm{f}$ [21]. Figure 7 gives the results of EPMA line analysis across the grain boundaries in the samples with $\mathrm{CR}$ of $0.01{ }^{\circ} \mathrm{C} / \mathrm{s}$. Enhanced levels of $\mathrm{Cr}, \mathrm{W}$ and Mo in UHSS A (Fig. 7c) and $\mathrm{W}$ in UHSS B (Fig. 7d) are detected. FESEM-EDS analyses shown in Fig. 8 reveal that these enhanced levels of $\mathrm{Cr}, \mathrm{W}$ and Mo are related to the formation of proeutectoid alloy-rich carbides at PAG boundaries as a result of the slow cooling rate. In the case of UHSS A, two types of proeutectoid carbides are observed: complex carbides rich in $\mathrm{Fe}, \mathrm{W}$ and $\mathrm{Mo}$ and iron carbides containing some $\mathrm{Cr}$. In UHSS $\mathrm{B}$, carbides at PAG 

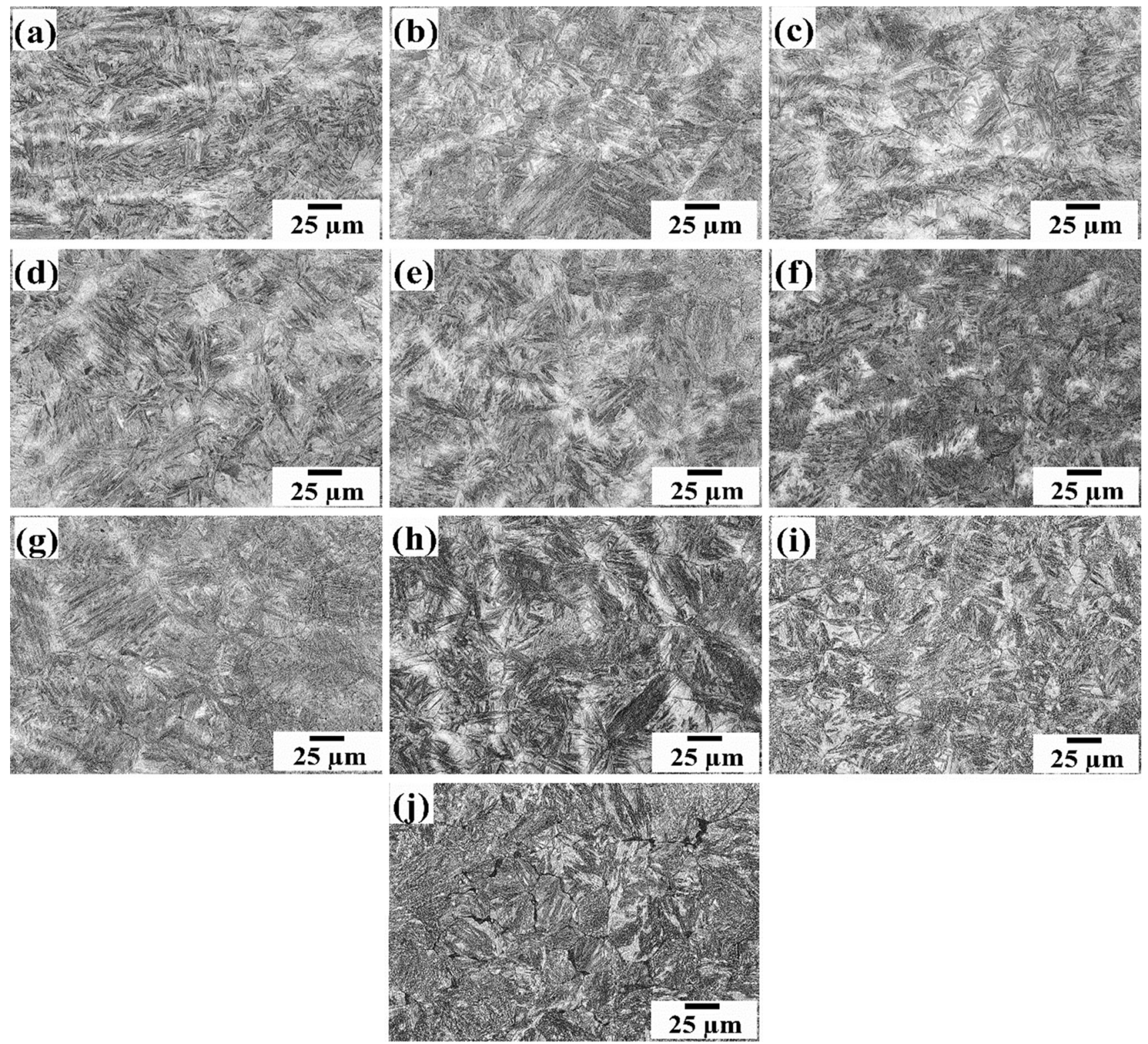

Fig. 3 LSCM micrographs of UHSS A with cooling rates of $60(\mathbf{a}), 30(\mathbf{b}), 15(\mathbf{c}), 5(\mathbf{d}), 1(\mathbf{e}), 0.6(\mathbf{f}), 0.2(\mathbf{g}), 0.08(\mathbf{h}), 0.02(\mathbf{i})$ and $0.01{ }^{\circ} \mathrm{C} / \mathrm{s}(\mathbf{j})$

boundaries are much less common than those in UHSS A as can be seen by comparing with Figs. $3 \mathrm{j}, 4 \mathrm{j}$, and $8 \mathrm{a}$, b. It is presumably due to the lower C and Cr contents of UHSS B. Some carbides are observed to mainly contain iron with only low levels of $\mathrm{Cr}, \mathrm{W}$ and Mo.

Support for the conclusion that the carbides are proeutectoid in nature is provided by thermodynamic calculations using the commercial software Thermo-Calc together with TCFE7 database shown in Fig. 9. Table 2 shows the predicted volume fraction of carbides in equilibrium with austenite at $755^{\circ} \mathrm{C}$. It can be seen that the compositional difference between the steels, especially their $\mathrm{C}$ and $\mathrm{Cr}$ contents, results in clear difference in the predicted equilibrium volume fractions and composition of the carbides.
Even if equilibrium compositions and volume fractions were not achieved during cooling at $0.01{ }^{\circ} \mathrm{C} / \mathrm{s}$, the relative volume fractions shown in Table 2 are in line with the observation that UHSS A shows a clearly higher incidence of proeutectoid carbides than UHSS B.

Figure 10 shows combined EBSD inverse pole figures (IPF) and image quality (IQ) maps of the investigated steels with different cooling rates. Figure 11 shows grain boundary misorientation distributions, lath sizes, effective grain sizes and effective grain sizes at $90 \%$ in the cumulative grain size distribution for the investigated steels at different cooling rates. Table 3 summarizes the reconstructed PAGS, volume fractions of retained austenite and their carbon contents. 

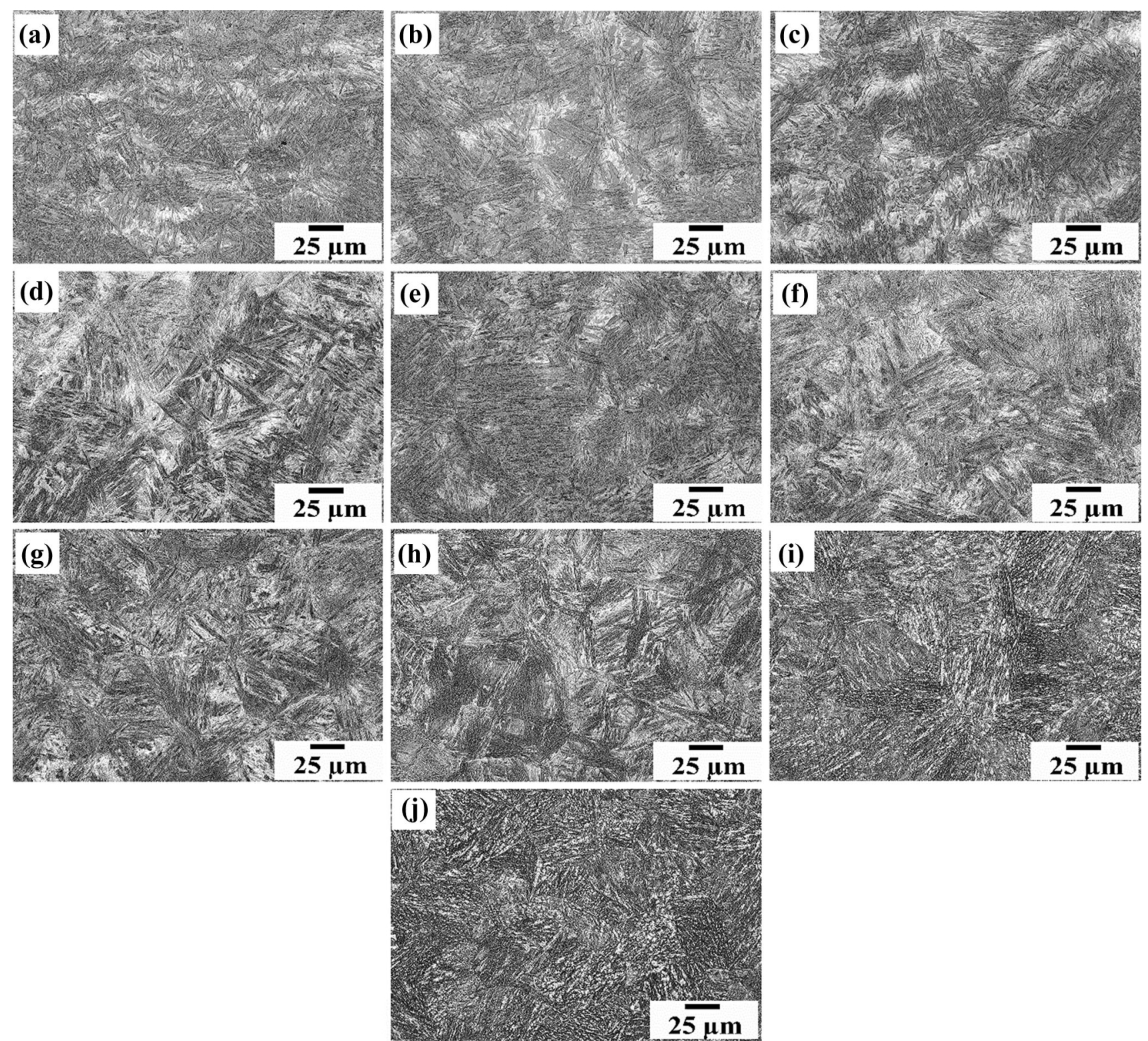

Fig. 4 LSCM micrograph of UHSS B with cooling rates of $60(\mathbf{a}), 30(\mathbf{b}), 15(\mathbf{c}), 5(\mathbf{d}), 1(\mathbf{e}), 0.6(\mathbf{f}), 0.2(\mathbf{g}), 0.08(\mathbf{h}), 0.02(\mathbf{i})$ and $0.01{ }^{\circ} \mathrm{C} / \mathrm{s}(\mathbf{j})$
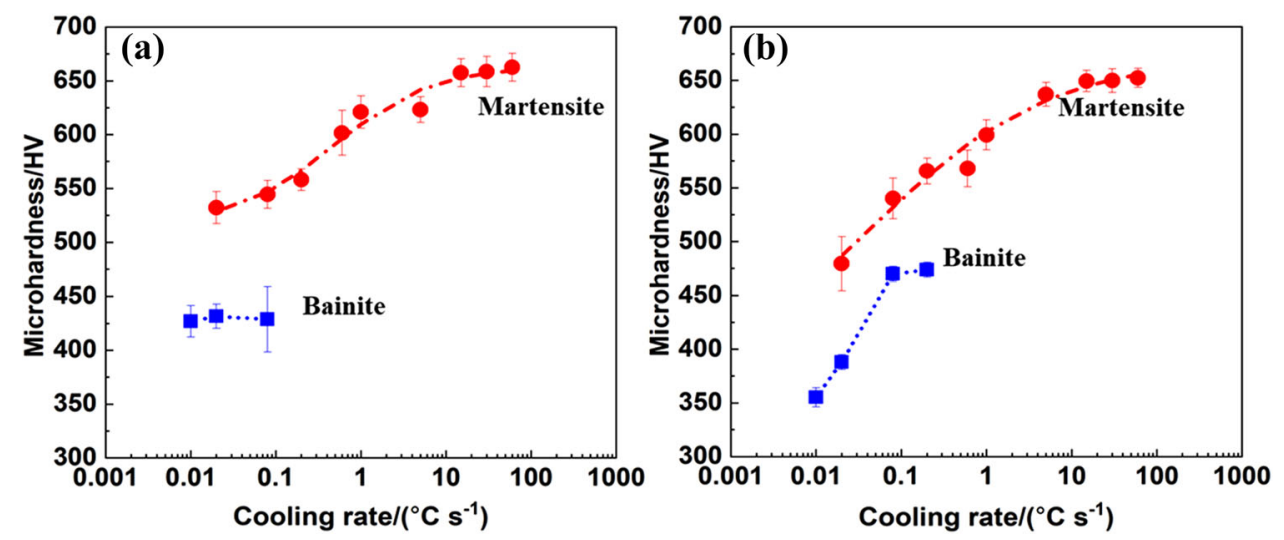

Fig. 5 Effect of cooling rate on microhardness of martensite and bainite in UHSS A (a) and UHSS B (b) 

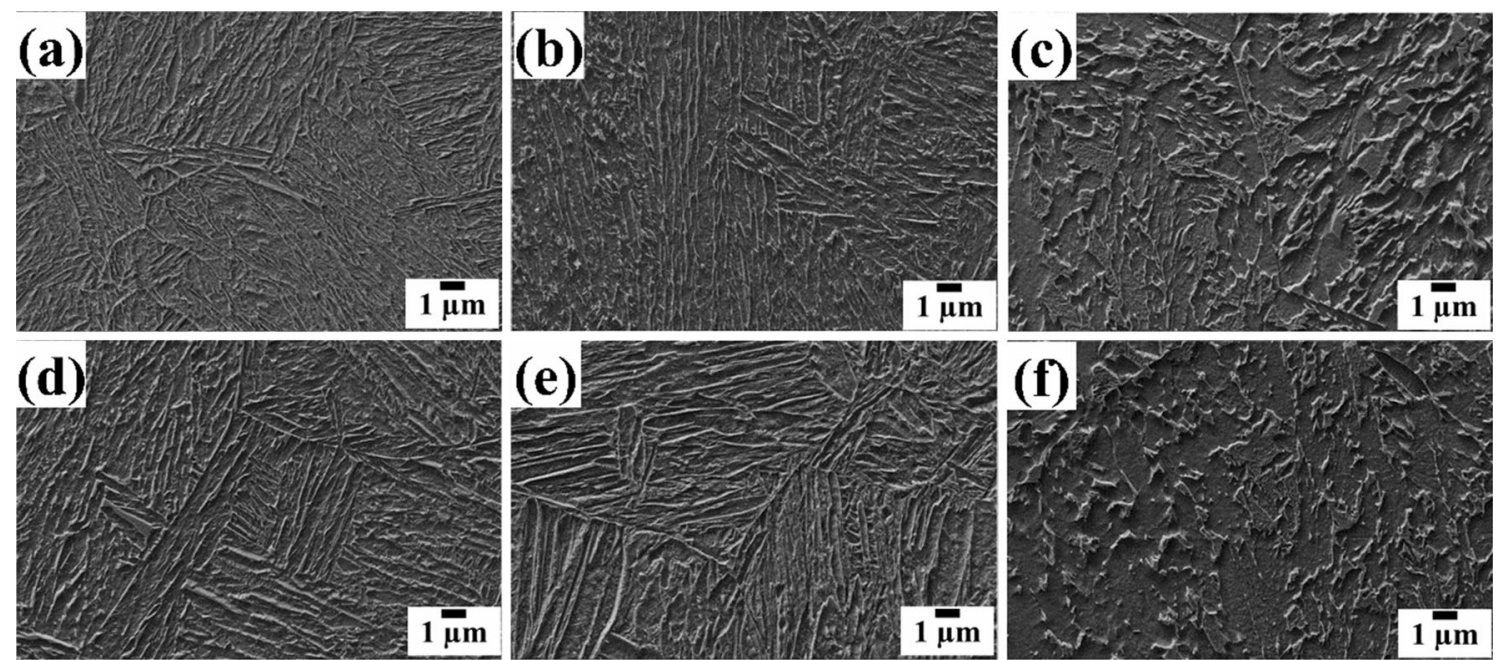

Fig. 6 SEM micrographs of UHSS A (a-c) and UHSS B (d-f) with cooling rates of $60(\mathbf{a}, \mathbf{d}), 1(\mathbf{b}, \mathbf{e})$ and $0.01{ }^{\circ} \mathrm{C} / \mathrm{s}(\mathbf{c}, \mathbf{f})$. Plane of micrographs is parallel to forged bar axis
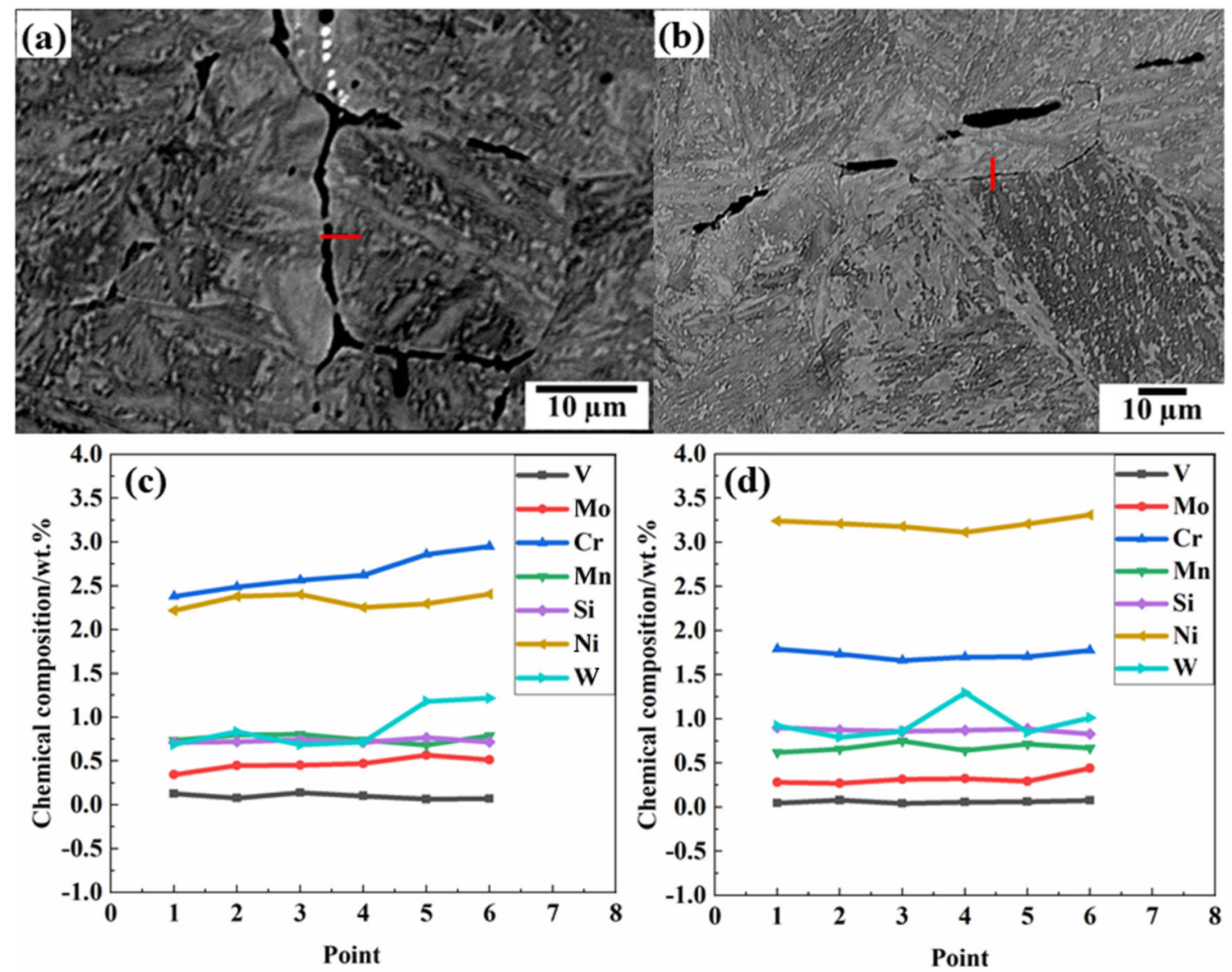

Fig. 7 EPMA micrograph and line analysis across grain boundaries of UHSS A (a, c) and UHSS B (b, d) with cooling rate of $0.01{ }^{\circ} \mathrm{C} / \mathrm{s}$

In the case of UHSS A, as shown in Figs. 10 and 11, the microstructural parameters are changed as a result of cooling rate. As can be seen from Fig. 11a, the average ECD martensitic lath sizes are increased slightly from 0.88 to $0.98 \mu \mathrm{m}$ when the cooling rate decreased from 60 to $1{ }^{\circ} \mathrm{C} / \mathrm{s}$, while the effective (high-angle grain boundary) grain size increased from 1.04 to $1.23 \mu \mathrm{m}$. The value D90\% describes the effective grain size at $90 \%$ in the 


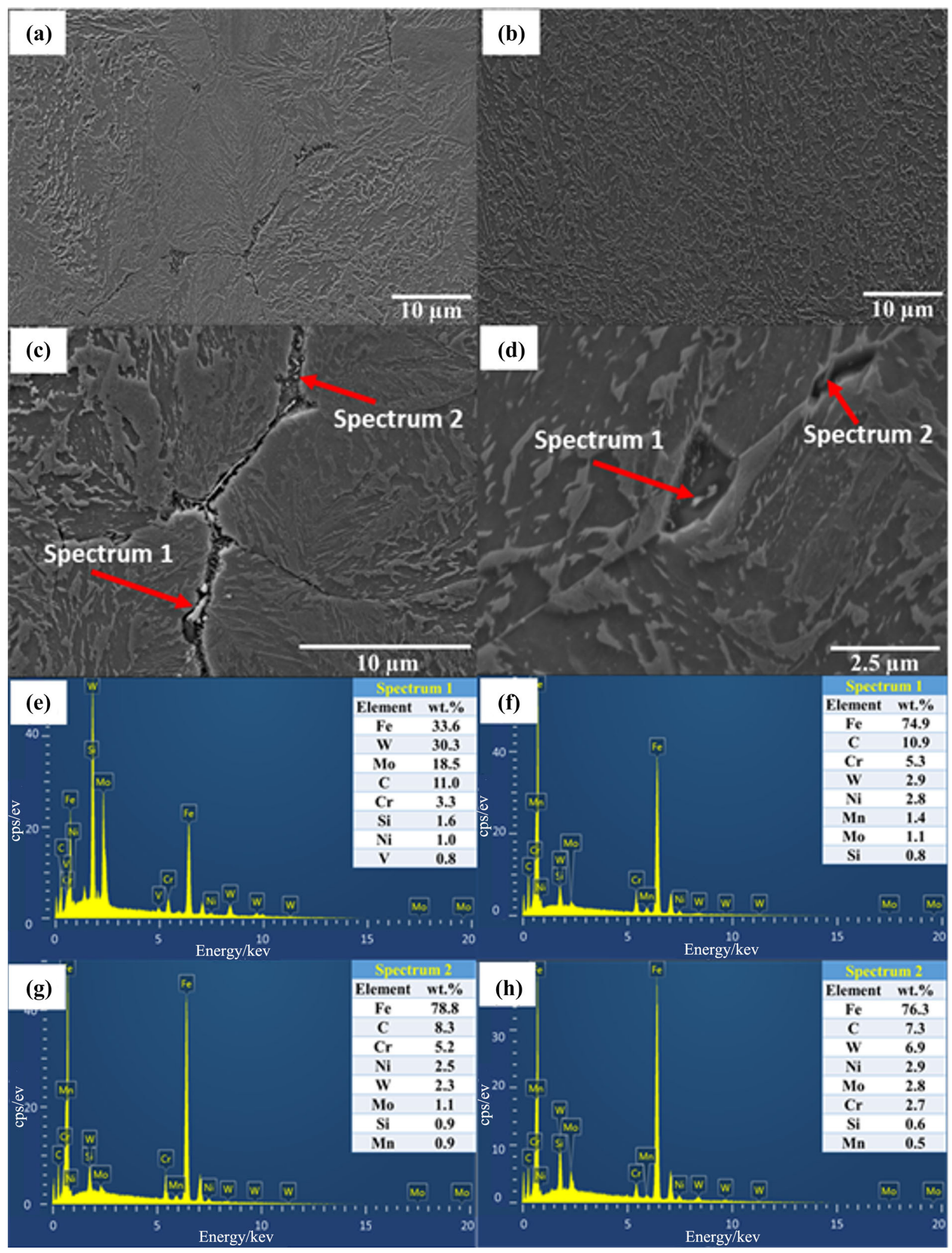

Fig. 8 Morphology and EDS analysis of carbides formed at prior austenite grain boundaries in UHSS A (a, c, e, g) and in UHSS B (b, d, f, h) at cooling rate from austenitization temperature $\left(950{ }^{\circ} \mathrm{C}\right)$ of $0.01{ }^{\circ} \mathrm{C} / \mathrm{s}$ 

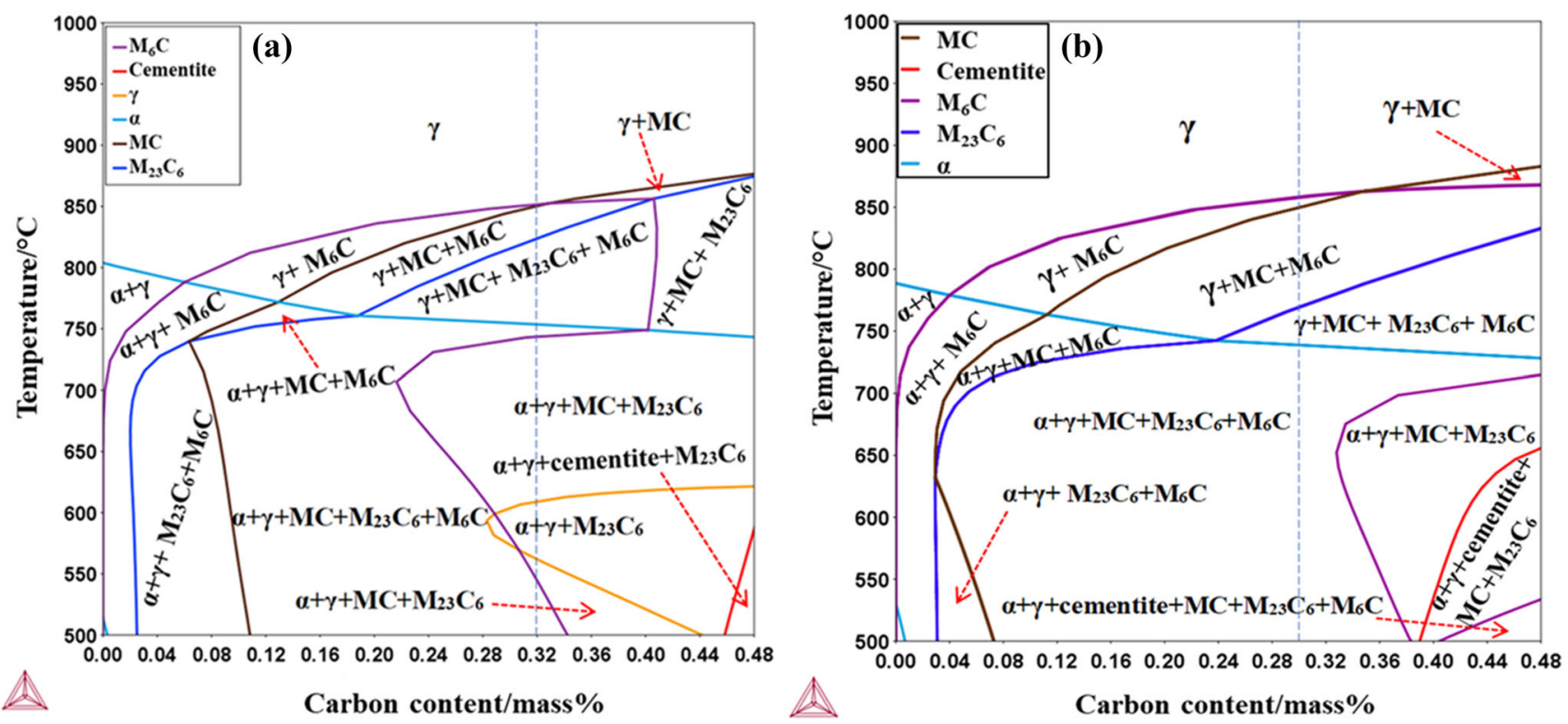

Fig. 9 Calculated equilibrium phase diagrams of investigated steels considering $\mathrm{C}, \mathrm{Cr}, \mathrm{Ni}, \mathrm{W}, \mathrm{Mn}$, Mo and V. Dashed line indicates $\mathrm{C}$ content. $\gamma$ Austenite; $\alpha$ ferrite

Table 2 Volume fraction of carbides formed with austenite at $755{ }^{\circ} \mathrm{C}$

\begin{tabular}{llll}
\hline Carbides & Chemical constitution & Volume fraction of carbides/vol.\% \\
\cline { 3 - 4 } & & UHSS A & UHSS B \\
\hline $\mathrm{MC}$ & $(\mathrm{V}, \mathrm{W})_{1}(\mathrm{C})_{1}$ & 0.001 & 0.001 \\
$\mathrm{M}_{23} \mathrm{C}_{6}$ & $(\mathrm{Fe}, \mathrm{Cr})_{20}(\mathrm{~W}, \mathrm{Mo})_{3}(\mathrm{C})_{6}$ & 0.018 & 0.004 \\
$\mathrm{M}_{6} \mathrm{C}$ & $(\mathrm{Fe})_{2}(\mathrm{~W}, \mathrm{Mo})_{2}(\mathrm{Fe}, \mathrm{W}, \mathrm{Mo}, \mathrm{Cr})_{2}(\mathrm{C})_{1}$ & 0.002 & 0.006 \\
Total & & 0.021 & 0.012 \\
\hline
\end{tabular}

cumulative size distribution. This value can be calculated based on the number of grains $\mathrm{D} 90 \%_{(\mathrm{GN})}$ which we used in earlier publication [10] or calculated based on the cumulative grain area definition D90\% $(\mathrm{GA})$. Both $\mathrm{D} 90 \%_{(\mathrm{GN})}$ and D $90 \%_{(\mathrm{GA})}$ are calculated based on EBSD data for grains with misorientation angles higher than $15^{\circ}$. In the case of D $90 \%{ }_{(\mathrm{GN})}$, all grains have the same weight, and $90 \%$ of the grains have an ECD less than D90\% ${ }_{(\mathrm{GN})}$. However, in the case of $\mathrm{D} 90 \%_{(\mathrm{GA})}$, each grain is weighted according to its area, and D90\% $(\mathrm{GA})$ is ECD below which $90 \%$ of the cumulative area of all grains is located. In other words, $10 \%$ of the sample cross section contains grains larger than D $90 \%_{(\mathrm{GA})}$. Now, we prefer to use D90\%(GA) because it gives more weight to the larger grains, while $\mathrm{D} 90 \%_{(\mathrm{GN})}$ is very sensitive to the cutoff grain size used at the lower end of the grain size distribution. Both values are given in Fig. 11a, b. As can be seen from Fig. 11a, D90\% ${ }_{(\mathrm{GA})}$ increased from 4.8 to $6.9 \mu \mathrm{m}$ when the cooling rate decreased from 60 to $1{ }^{\circ} \mathrm{C} / \mathrm{s}$. PAGS increased from 19.8 to $26.2 \mu \mathrm{m}$ resulting from more extensive grain growth during the longer time at temperatures below $950{ }^{\circ} \mathrm{C}$ at the slower cooling rate [20], see Fig. 12a, b and Table 3. At the slowest cooling rate of $0.01{ }^{\circ} \mathrm{C} / \mathrm{s}$, the above parameters are quite different as PAGS increased significantly to $46.2 \mu \mathrm{m}$. The microstructure is now fully bainite with the average ECD bainitic lath size, effective grain size (EGS) and $\mathrm{D} 90 \%_{(\mathrm{GA})}$ equal to $1.01,1.06$ and $12.65 \mu \mathrm{m}$, respectively. The opposite trends observed regarding the effect of cooling rate on $\mathrm{D} 90 \%_{(\mathrm{GN})}$ and $\mathrm{D} 90 \%_{(\mathrm{GA})}$ for the two slowest cooling rates are due to the difference in the grain size distributions: Compared to $\mathrm{CR}$ of $1{ }^{\circ} \mathrm{C} / \mathrm{s}$, at $0.01{ }^{\circ} \mathrm{C} / \mathrm{s}$, the grain size distribution contains a larger number of small grains, which causes a reduction in D90\% $(\mathrm{GN})$, as well as an increase in the size of the largest grains, which leads to an increase in $\mathrm{D} 90 \%(\mathrm{GA})$.

Changes in cooling rate have similar effects on the microstructural features of UHSS B: PAGS increased from 35.5 to $36.9 \mu \mathrm{m}$ as $\mathrm{CR}$ decreased from 60 to $1^{\circ} \mathrm{C} / \mathrm{s}$. As shown in Fig. 11b, the average ECD martensitic lath size, EGS and D90\% increased from $0.75,0.98$ and $4.4 \mu \mathrm{m}$ to $0.88, \quad 1.08$ and $5.6 \mu \mathrm{m}$, respectively, while these microstructural features for the bainite obtained at the 


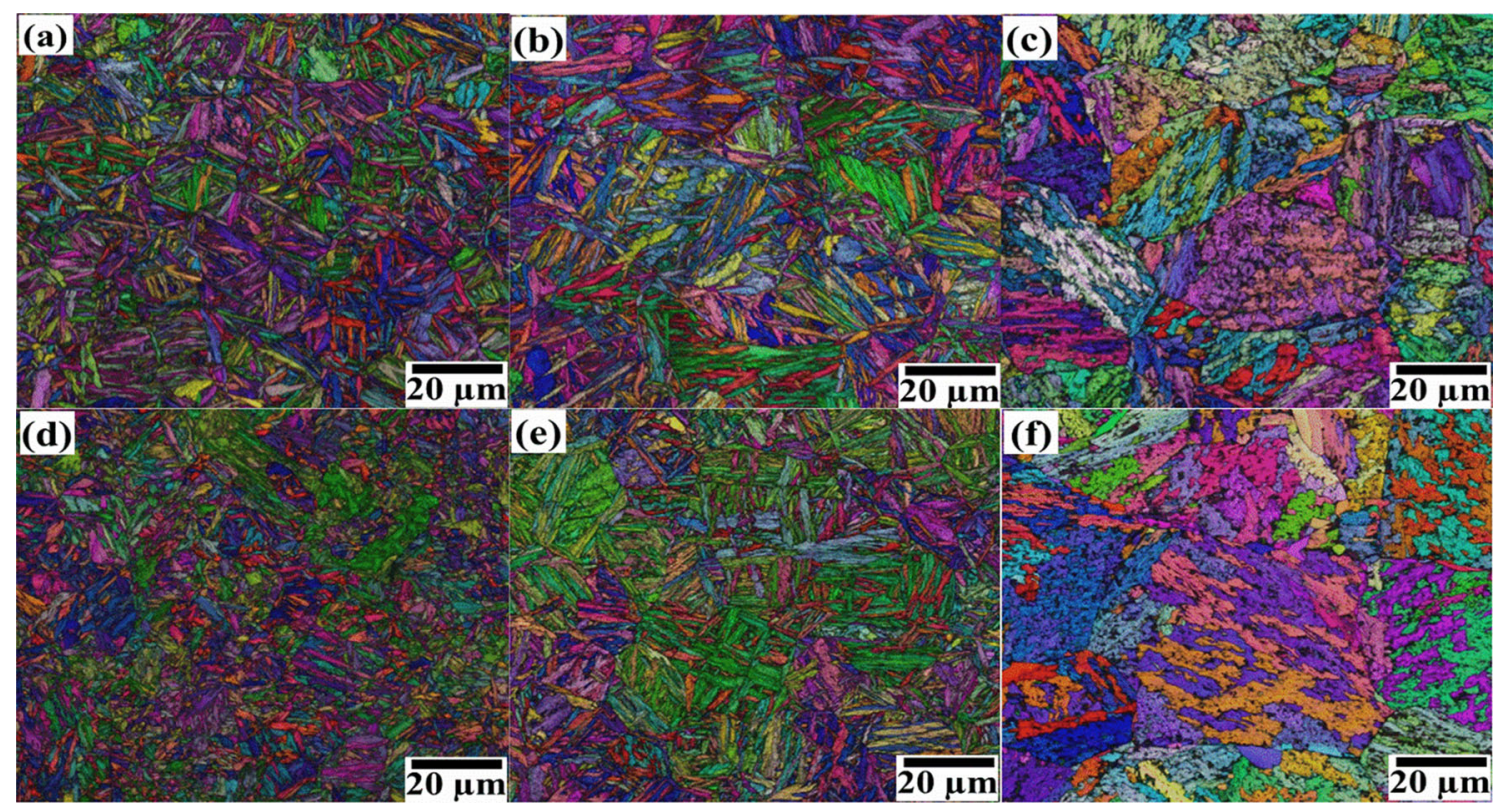

Fig. 10 IPF combined with IQ map of UHSS A (a-c) and UHSS B (d-f) with CR of $60(\mathbf{a}, \mathbf{d}), 1(\mathbf{b}, \mathbf{e})$ and $0.01{ }^{\circ} \mathrm{C} / \mathrm{s}(\mathbf{c}, \mathbf{f})$. Plane of micrographs is parallel to axis of forged bars
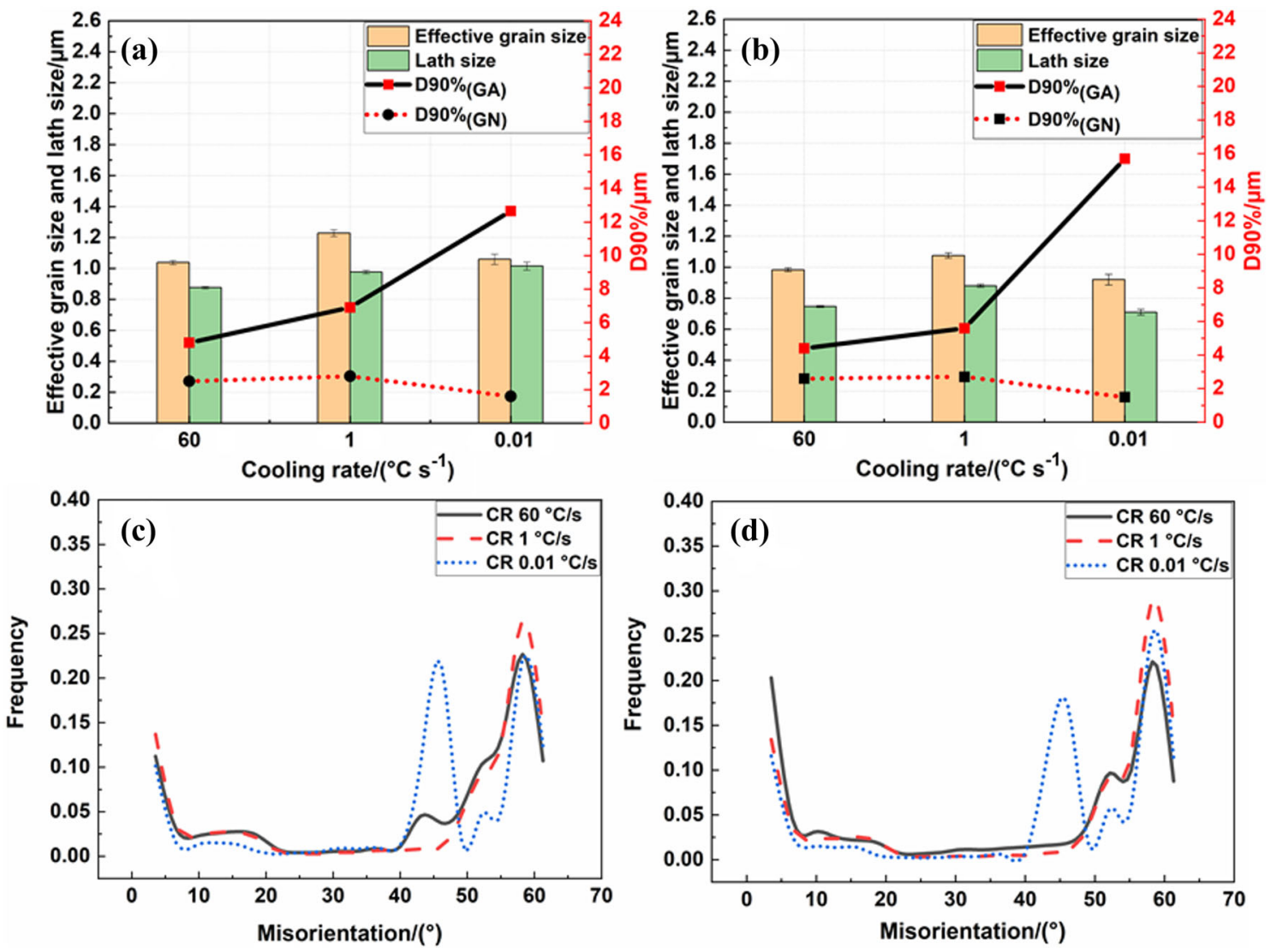

Fig. 11 Average lath size, average effective grain size and effective grain size at $90 \%$ in cumulative grain size distribution (a, b) together with grain boundary misorientation distributions $(\mathbf{c}, \mathbf{d})$ for UHSS A $(\mathbf{a}, \mathbf{c})$ and UHSS B $(\mathbf{b}, \mathbf{d})$ 
Table 3 Prior austenite grain sizes (PAGS), volume fractions of RA $\left(V_{\gamma}\right)$ and $C_{\gamma}$ for investigated steels at different cooling rates

\begin{tabular}{lllrr}
\hline Steel & Cooling rate $/\left({ }^{\circ} \mathrm{C} \mathrm{s}^{-1}\right)$ & PAGS $/ \mu \mathrm{m}$ & $V_{\gamma}^{\mathrm{b}} / \%$ & \multicolumn{1}{c}{$C_{\gamma} / \%$} \\
\hline UHSS A & 60 & $19.83 \pm 1.40$ & $4.60 \pm 0.30$ & 0.21 \\
& 1 & $26.18 \pm 1.18$ & $5.08 \pm 0.19$ \\
UHSS B & 0.01 & $46.21 \pm 7.57$ & $17.16 \pm 0.12$ & 0.41 \\
& 60 & $35.53 \pm 3.64$ & $2.30 \pm 1.10$ & 0.85 \\
& 1 & $36.89 \pm 1.76$ & $2.33 \pm 0.11$ & 0.36 \\
& 0.01 & $55.04 \pm 4.49$ & $12.25 \pm 0.11$ & 0.82
\end{tabular}

${ }^{a}$ Error bars are $95 \%$ confidence intervals for mean value

${ }^{\mathrm{b}}$ Error bars are standard deviations

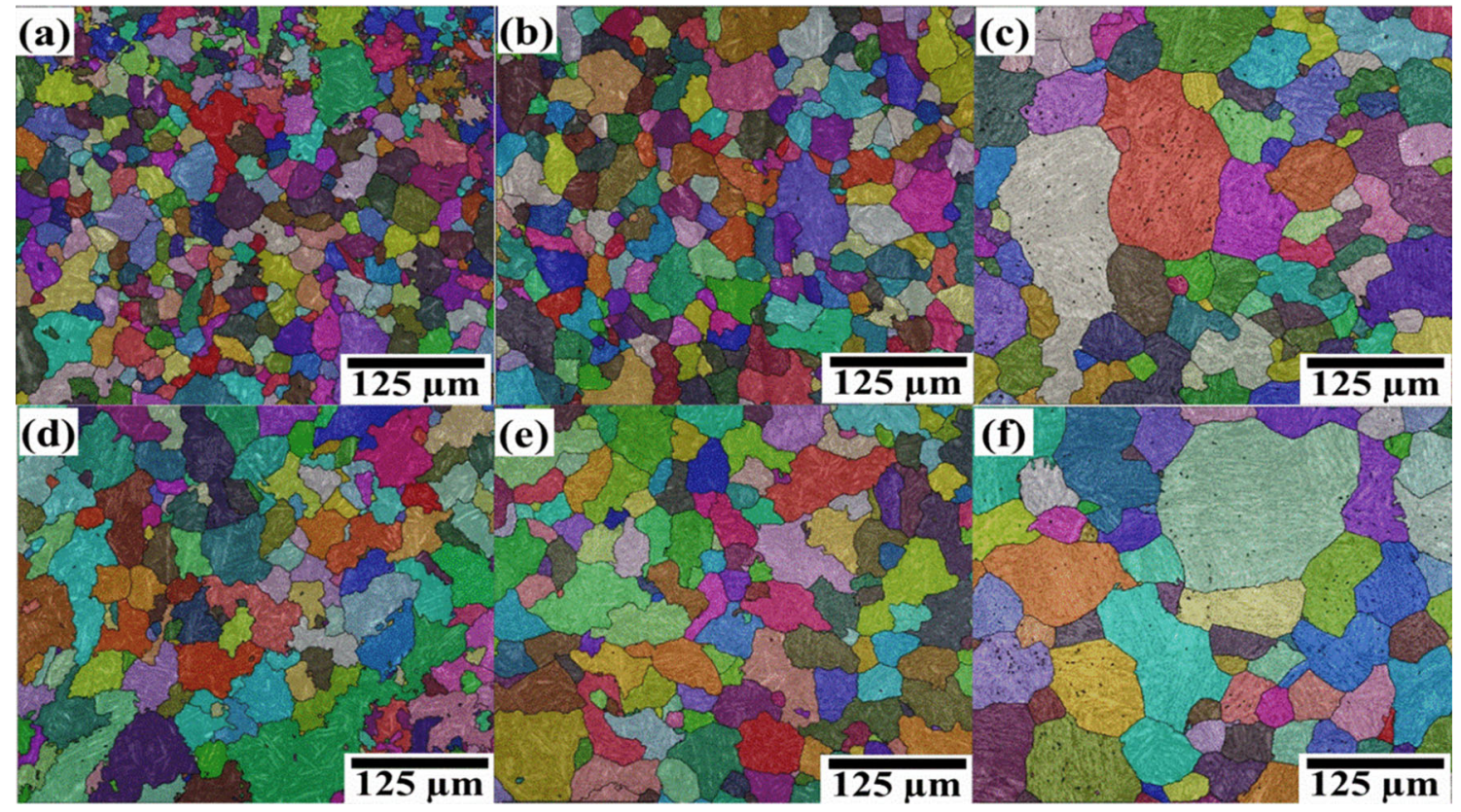

Fig. 12 Reconstructed PAG using EBSD results together with MTEX and MATLAB software for UHSS A (a-c) and UHSS B (d-f) with CR of $60(\mathbf{a}, \mathbf{d}), 1(\mathbf{b}, \mathbf{e})$, and $0.01^{\circ} \mathrm{C} / \mathrm{s}(\mathbf{c}, \mathbf{f})$. Plane of micrographs is parallel to axis of forged bars

slowest cooling rate become $0.71,0.92$ and $15.7 \mu \mathrm{m}$, respectively, and PAGS is $55.0 \mu \mathrm{m}$. The mean EGSs are somewhat smaller in the case of the bainitic microstructure than in the martensitic microstructures. This may result from the strengthening of the austenite during transformation to bainite due to a concomitant increase in its carbon content resulting in a decrease in the bainitic block size [22]. This effect is also seen in the higher frequency of high-angle boundary peaks in bainite compared to that in martensite (see Fig. 11c, d). The effect of cooling rate on PAGS and D90\% is shown in Fig. 13. In both investigated steels, as the cooling decreased, both PAGS and D90\% increased sharply. Also, Fig. 13 shows that there are strong correlations between PAGS and D90\%. These results are in line with the commonly observed reduction in block and packet size resulting from a refinement of PAGS [23]. The difference in PAGS (see Table 3 ) is probably due to the large time difference that the austenite spends at high temperatures before the phase transformations begin. For example, to decrease the temperature from 950 to $900{ }^{\circ} \mathrm{C}$, $83,0.83$ and $0.016 \mathrm{~min}$ are required for CRs of $0.01,1$ and $60{ }^{\circ} \mathrm{C} / \mathrm{s}$, respectively. The difference in PAGS is particularly noticeable between CRs of 1 and $0.01{ }^{\circ} \mathrm{C} / \mathrm{s}$.

For both steels, the lath and mean effective grain sizes are only slightly affected by $\mathrm{CR}$; they mainly depend on the type of microstructure formed and not on the changes in PAGS [24]. They increased slightly in the case of the fully martensitic structures when the cooling rate decreased from 60 to $1{ }^{\circ} \mathrm{C} / \mathrm{s}$. However, with a further decrease in the cooling rate to $0.01{ }^{\circ} \mathrm{C} / \mathrm{s}$, the formation of bainite led to a 


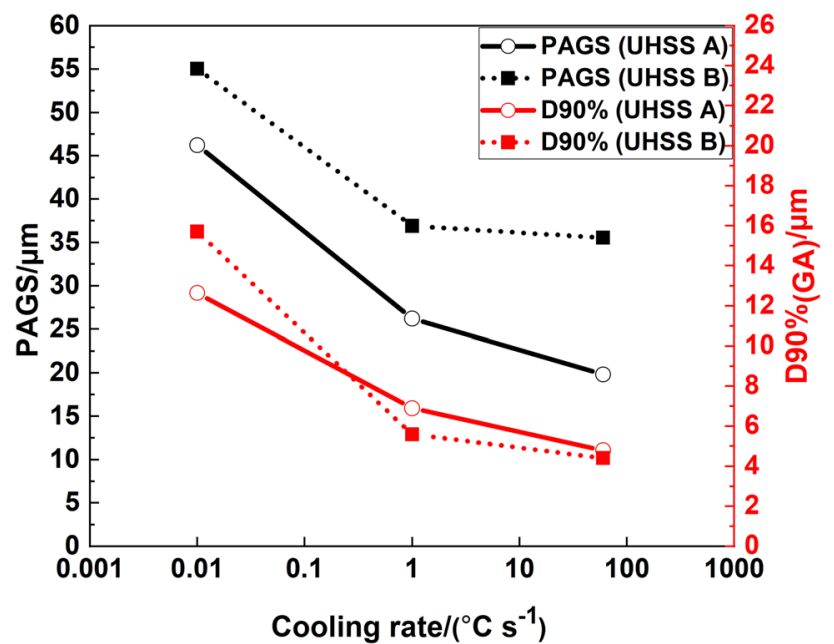

Fig. 13 Effect of cooling rate on PAGS and D90\% of UHSS A and UHSS B

decrease in their values. The current results show that there is a strong correlation between PAGS and D90\% based on the cumulative grain area, which increased sharply when $\mathrm{CR}$ was at its lowest.

From Fig. 11a, b, it can be seen that although PAGS of UHSS A are lower than those of UHSS B, the lath and mean effective grain sizes in UHSS A are higher than those in UHSS B, which confirms the above conclusion that the lath and mean effective grain sizes are not dependent on the PAGS but depend on the chemical composition and whether bainite or martensite forms.

Figure 14 and Table 3 show that RA percentage is small and practically independent of $\mathrm{CR}$ in the case of the martensitic microstructures, i.e., at 60 and $1{ }^{\circ} \mathrm{C} / \mathrm{s}$, but appreciable amounts of RA are found when the microstructure is bainite. The formation of RA in bainite is assisted by the presence of approximately $0.6 \% \mathrm{Si}$ in the steel, known to reduce the kinetics of cementite precipitation from austenite [25-27]. Also, it is assisted by the very slow cooling rate [28] and the presence of $\mathrm{Ni}$, both of which are known to help stabilize RA [29]. Slower cooling rates give more time for carbon diffusion into and within the austenite [30]. All these factors can increase the stability of austenite and reduce its probability for full transformation. Also, the presence of the granular bainite may contribute to the stability of the retained austenite [31].

\subsection{Mechanical properties of UHSSs A and B}

The mechanical properties of the investigated steels after the thermal cycles (shown in Fig. 1) with cooling rates of 60,1 and $0.01{ }^{\circ} \mathrm{C} / \mathrm{s}$, and the temperatures for $50 \%$ transformation are presented in Table 4, Figs. 15 and 16, respectively. As commonly observed [24], the hardness, ultimate tensile strength (UTS) and yield strength (YS)

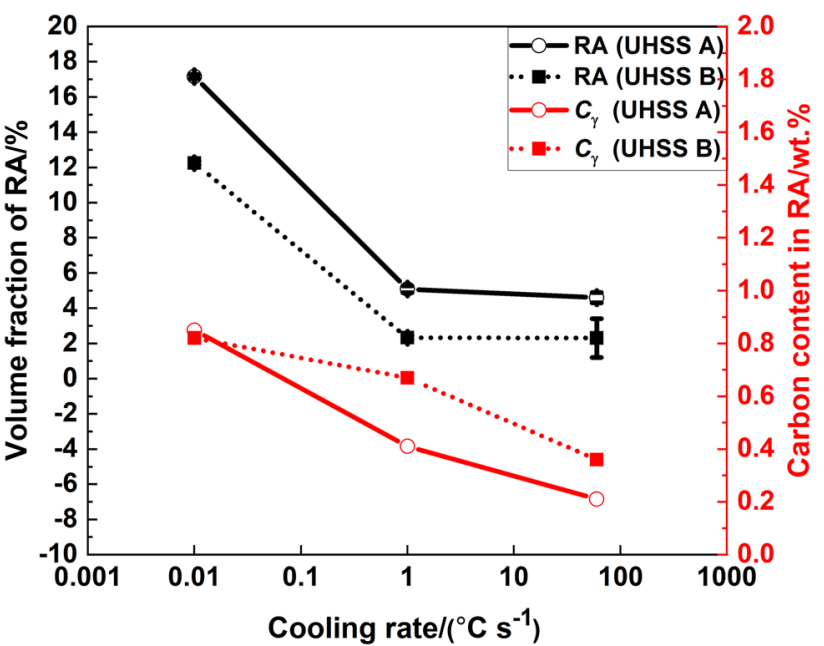

Fig. 14 Effect of cooling rates on volume fraction of RA for UHSSs $\mathrm{A}$ and $\mathrm{B}$

increase as the transformation temperature drops with increasing CR. This trend is due to various interrelated factors such as increasing carbon content and other alloying elements in solid solution in the martensite, as well as refinement of the martensite lath and prior austenite grain sizes. These results are in good agreement with the results obtained by Kennett and Findley [32] who conclude that strength is increased with refinement of PAGS in microalloyed ASTM A514 steel in the as-quenched and low-temperature tempered state. Lan et al. [33] observed that YS and UTS of a low-carbon bainitic steel increased due to the refinement of PAGS, packets and blocks. Sun et al. [34] stated that the effective grain size (block size) is the controlling factor for YS and toughness of martensitic steel. In addition to the above parameters, lower strength and hardness result from the appearance of granular bainite with proeutectoid carbides at PAG boundaries. Also, the formation of grain boundary carbides may lead to a decrease in toughness. Increasing the cooling rates leads to an improvement of the strength, but elongation to fracture (El) is decreased because of the presence of hard martensite.

The toughness properties including impact toughness at room temperature and $-40{ }^{\circ} \mathrm{C}$ and ductile fracture (DF) percentage are increased when the cooling rate increased from 0.01 to $1{ }^{\circ} \mathrm{C} / \mathrm{s}$ and then decreased when CR increased to $60{ }^{\circ} \mathrm{C} / \mathrm{s}$. The same trend was observed by Kumar et al. [20]. The decrease in toughness at the highest cooling rate $\left(60{ }^{\circ} \mathrm{C} / \mathrm{s}\right)$ may be attributed to the very high strength values, and the presence of less retained austenite compared with the other cooling rates [35]. The lowest cooling rate $\left(0.01{ }^{\circ} \mathrm{C} / \mathrm{s}\right)$ shows the lowest toughness even though it is associated with the lowest values of strength and highest retained austenite contents. This is probably due to the large $\mathrm{D} 90 \%_{(\mathrm{GA})}$, associated with the large PAGS, the 
Table 4 Mechanical properties of UHSSs A and B with cooling rates of 60,1 and $0.01{ }^{\circ} \mathrm{C} / \mathrm{s}$

\begin{tabular}{|c|c|c|c|c|c|c|c|c|c|c|}
\hline Steel & $\begin{array}{l}\text { Cooling } \\
\text { rate } /\left({ }^{\circ} \mathrm{C}\right. \\
\left.\mathrm{s}^{-1}\right)\end{array}$ & $\mathrm{UTS}^{\mathrm{a}} / \mathrm{MPa}$ & $\mathrm{YS}^{\mathrm{a}} / \mathrm{MPa}$ & $\mathrm{El}^{\mathrm{a}} / \%$ & $\begin{array}{l}\text { YS/ } \\
\text { UTS }\end{array}$ & $\begin{array}{l}\text { CVN impact } \\
\text { energy at } \mathrm{RT}^{\mathrm{a}} / \\
\left(\mathrm{J} \mathrm{cm}^{-2}\right)\end{array}$ & $\begin{array}{l}\mathrm{DF} \text { at } \\
\mathrm{RT}^{\mathrm{b}} / \%\end{array}$ & $\begin{array}{l}\text { CVN impact energy } \\
\text { at }-40{ }^{\circ} \mathrm{C}^{\mathrm{a}} /\left(\mathrm{J} \mathrm{cm}^{-2}\right)\end{array}$ & $\begin{array}{l}\mathrm{DF} \text { at } \\
-40^{\circ} \mathrm{C}^{\mathrm{b}} / \\
\%\end{array}$ & $\begin{array}{l}\text { Hardness }{ }^{\mathrm{c}} / \\
\text { HV10 }\end{array}$ \\
\hline \multirow{3}{*}{$\begin{array}{l}\text { UHSS } \\
\text { A }\end{array}$} & 0.01 & $1417 \pm 3$ & $800 \pm 11$ & $14 \pm 0$ & 0.56 & $21 \pm 2$ & 34 & $14 \pm 0$ & 11 & $417 \pm 5$ \\
\hline & 1 & $1978 \pm 16$ & $1205 \pm 65$ & $8 \pm 1$ & 0.61 & $24 \pm 2$ & 43 & $18 \pm 0$ & 29 & $578 \pm 3$ \\
\hline & 60 & $2109 \pm 2$ & $1343 \pm 86$ & $7 \pm 2$ & 0.64 & $18 \pm 0$ & 29 & $14 \pm 0$ & 20 & $635 \pm 6$ \\
\hline \multirow{3}{*}{$\begin{array}{l}\text { UHSS } \\
\text { B }\end{array}$} & 0.01 & $1351 \pm 10$ & $793 \pm 19$ & $19 \pm 0$ & 0.59 & $24 \pm 0$ & 25 & $15 \pm 1$ & 11 & $394 \pm 4$ \\
\hline & 1 & $1786 \pm 7$ & $1095 \pm 13$ & $9 \pm 1$ & 0.61 & $27 \pm 1$ & 51 & $21 \pm 1$ & 45 & $535 \pm 3$ \\
\hline & 60 & $1896 \pm 30$ & $1292 \pm 38$ & $10 \pm 2$ & 0.68 & $23 \pm 1$ & 39 & $17 \pm 1$ & 33 & $582 \pm 4$ \\
\hline
\end{tabular}

${ }^{\mathrm{a}}$ Error bars are standard deviations of three measurements

${ }^{\mathrm{b}}$ Ductile fracture was calculated according to ASTM A 370-11

${ }^{\mathrm{c}}$ Error bars are standard deviations of ten measurements
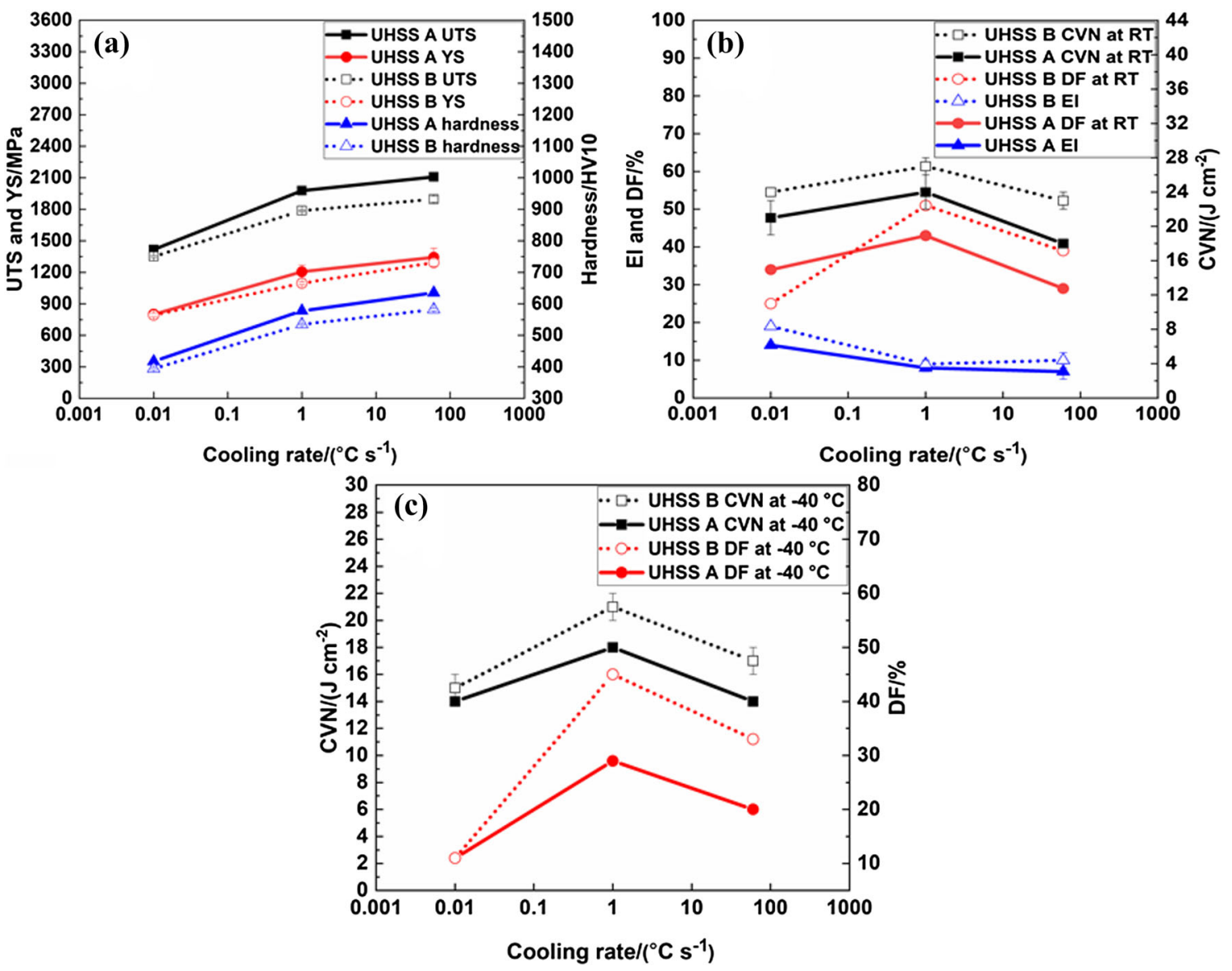

Fig. 15 Variation of mechanical properties with cooling rate

carbides formed at the grain boundaries and the appearance of granular bainite, which has low resistance to crack propagation due to its large crystallographic packet size and crack nucleation sites with coarse martensite-austenite (M-A) constituents [21, 36]. Similar results were found by Luo et al. [24] who studied the effect of different cooling rates (using water, oil, rapid air and sand cooling) on the substructure of mixed lath martensite-bainite microstructures in NiCrMoV low-carbon steels and the effect on the toughness properties. They suggested that the presence of granular bainite at the slowest cooling rate was responsible for a loss of toughness.

Since the two steels have received identical thermomechanical and heat treatments, the higher strength and lower 

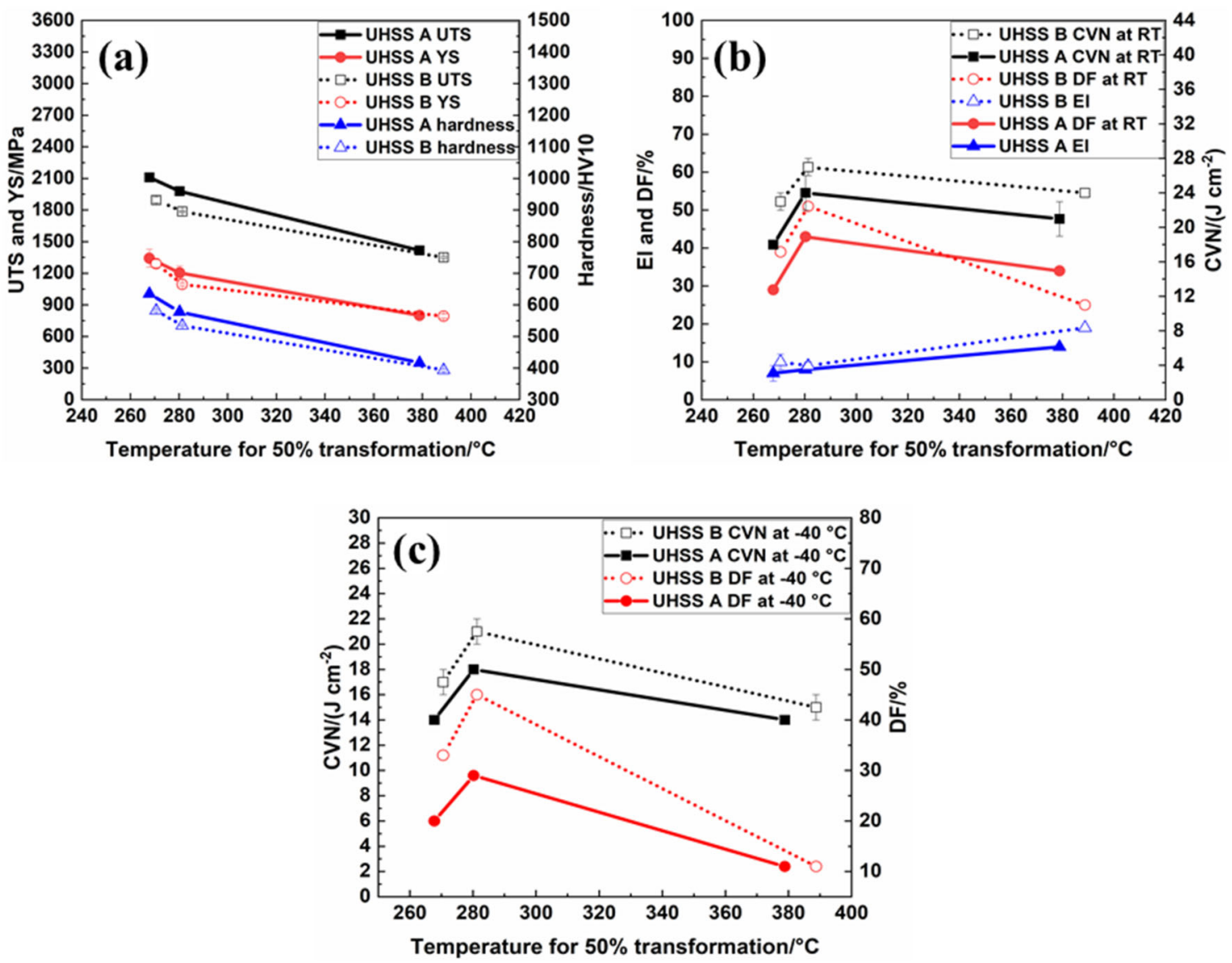

Fig. 16 Effect of 50\% transformation temperature on mechanical properties
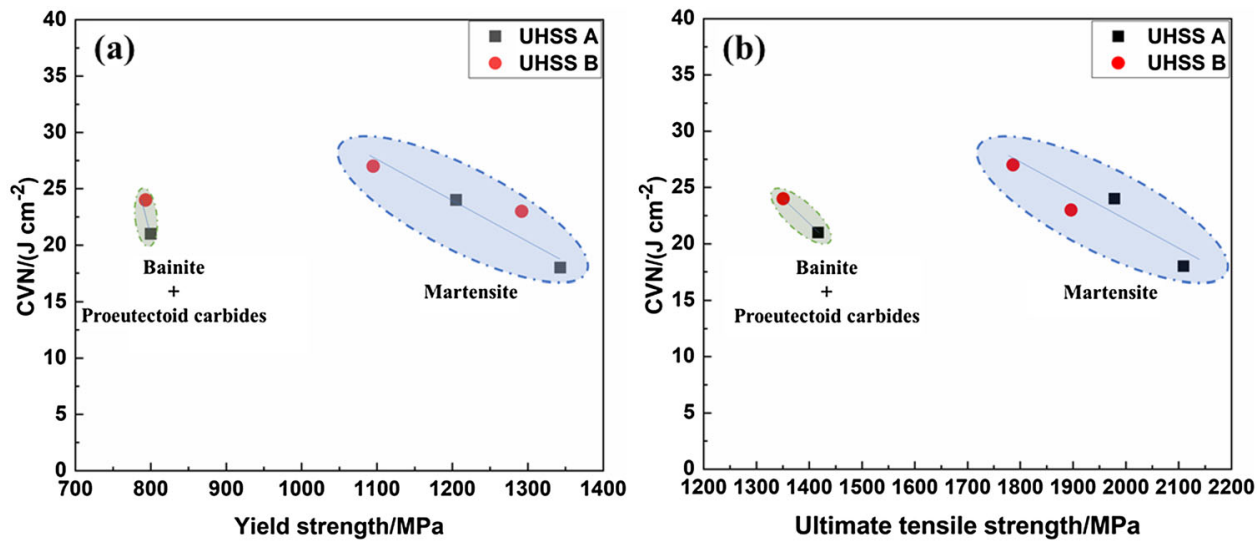

Fig. 17 Relationship between yield strength, ultimate tensile strength and impact toughness at room temperature

toughness of UHSS A compared to UHSS B are presumably a consequence of somewhat higher contents of $\mathrm{C}$ and $\mathrm{Cr}$ and lower content of $\mathrm{Ni}$ giving rise to the microstructural differences discussed above. The larger effective grain size of UHSS A, often associated with a lower strength, has presumably been countered by higher contributions from solid solution and precipitation strengthening, and possibly a greater transformation induced plasticity effect stemming from a higher content of RA.

The relationship between the yield strength and impact toughness at room temperature (RT) and $-40{ }^{\circ} \mathrm{C}$ is presented in Figs. 17 and 18. It is clear from the figures that for the martensitic microstructures, there is an inverse 

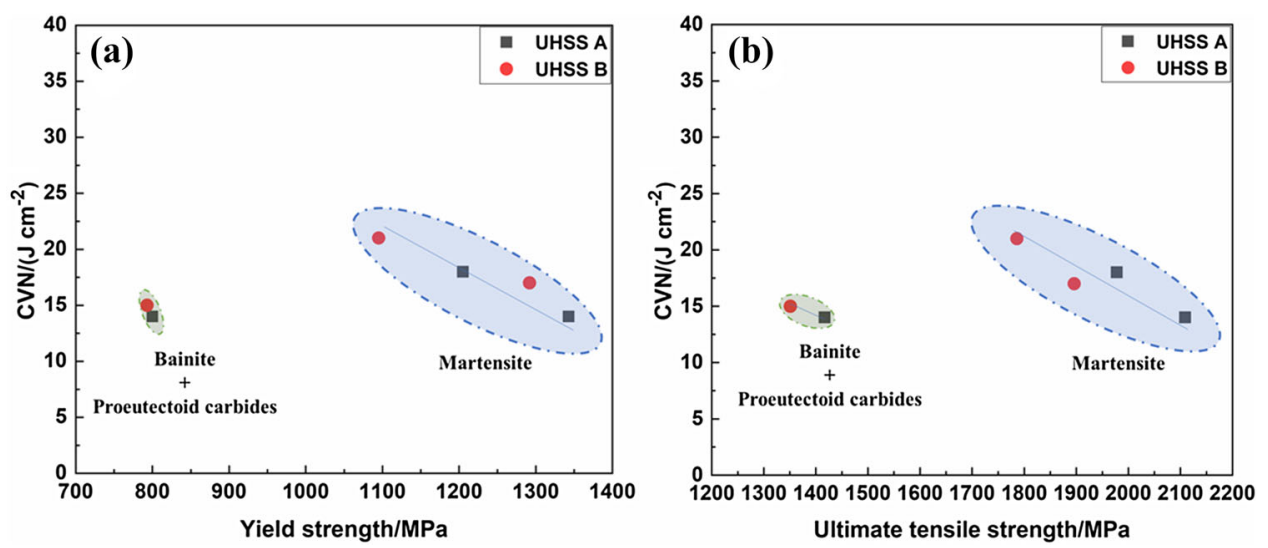

Fig. 18 Relationship between yield strength, ultimate tensile strength and impact toughness at $-40{ }^{\circ} \mathrm{C}$

relationship between yield or tensile strength and CVN impact toughness. The trend line for the martensitic microstructures does not extend to the bainitic microstructures obtained at the slowest cooling rate, however. In that case, impact toughness is poorer despite much lower yield and tensile strengths. Therefore, the best toughness is obtained with the lowest cooling rate that avoids the formation of bainite. This should be taken into account when designing practical parts and their cooling strategies.

\section{Conclusions}

1. For the steel with the highest $\mathrm{C}$ and $\mathrm{Cr}$ contents, fully martensitic microstructures were obtained down to cooling rates of $0.08{ }^{\circ} \mathrm{C} / \mathrm{s}$, but the hardness of the martensite decreased substantially as the cooling rate decreased. Mixtures of bainite and martensite form at cooling rates of $0.02{ }^{\circ} \mathrm{C} / \mathrm{s}$ or $0.08{ }^{\circ} \mathrm{C} / \mathrm{s}$ depending on the composition. In both steels, the main transformation products formed at $0.01{ }^{\circ} \mathrm{C} / \mathrm{s}$ were granular bainite with proeutectoid carbides formed at PAG boundaries.

2. RA percentage is small and practically independent of cooling rate in the case of martensitic microstructures, i.e., at 60 and $1{ }^{\circ} \mathrm{C} / \mathrm{s}$, but appreciable amounts are found when the microstructure is bainitic. This is due to the presence of approximately $0.6 \% \mathrm{Si}$ and $2-3 \%$ $\mathrm{Ni}$, and the very slow cooling rate involved.

3. Prior austenite grain size and the 90th percentile grain size in the cumulative grain area distribution (D90\%) decreased with increasing cooling rate because of the concomitant reduction in the time for grain growth between the end of austenitization and the beginning of phase transformation.

4. Refinement of the martensite lath size and effective grain size with increasing cooling rate leads to an increase in UTS, YS, YS/UTS ratio and hardness in both investigated steels. Low toughness at the highest cooling rate $\left(60^{\circ} \mathrm{C} / \mathrm{s}\right)$ is due to the very high strength combined with less retained austenite compared to slower cooling rates. At the lowest cooling rate $\left(0.01{ }^{\circ} \mathrm{C} / \mathrm{s}\right)$, low toughness despite low strength is due to a large PAGS, a large D90\% ${ }_{(\mathrm{GA})}$, the presence of prior austenite grain boundary carbides, and the appearance of granular bainite.

5. The steel with the higher $\mathrm{C}$ and $\mathrm{Cr}$ contents showed higher hardness and strength but with slightly lower toughness and elongation to fracture compared to the steel with the higher $\mathrm{Ni}$ content. The larger effective grain size of the steel with the higher $\mathrm{C}$ and $\mathrm{Cr}$ contents is compensated by higher solid solution and precipitation strengthening, thereby leading to higher strengths than obtained with the high-Ni steel.

6. The lower contents of $\mathrm{C}$ and $\mathrm{Cr}$ in the high-Ni steel led to lower volume fractions of proeutectoid carbides at PAG boundaries at the slowest cooling rate studied.

7. The best combination of strength and CVN impact toughness is achieved by choosing cooling rates that achieve a fully martensitic microstructure without the formation of granular bainite and proeutectoid grain boundary carbides.

Acknowledgements Open access funding provided by University of Oulu including Oulu University Hospital. The authors acknowledge the Egyptian Ministry of Higher Education (Cultural Affairs and Missions Sector) for financial support during this work.

Open Access This article is distributed under the terms of the Creative Commons Attribution 4.0 International License (http://crea tivecommons.org/licenses/by/4.0/), which permits unrestricted use, distribution, and reproduction in any medium, provided you give appropriate credit to the original author(s) and the source, provide a link to the Creative Commons license, and indicate if changes were made. 


\section{References}

[1] Y. Chen, J. Huang, X. Zhou, Z. Yang, in: International Conference on Logistics Engineering, Management and Computer Science, Atlantis Press, China, 2015, pp. 564-568.

[2] Y. Chen, Y. Zhao, X. Zhou, J. Huang, J. Wuhan Univ. Technol. Mater. Sci. Ed. 31 (2016) 387-392.

[3] G. Wang, Y. Yan, J. Li, J. Huang, Y. Su, L. Qiao, Corros. Sci. 77 (2013) 273-280.

[4] X.L. Zhao, Thin-Walled Struct. 37 (2000) 223-240.

[5] A.J. Kaijalainen, P. Suikkanen, L.P. Karjalainen, J.J. Jonas, Metall. Mater. Trans. A 45 (2014) 1273-1283.

[6] M. Dalmore, J.D. Ruhlman, Eglin steel-a low alloy high strength composition, US, 7537727B2, 2009.

[7] G. Vartanov, High strength military steel, US, 8414713B2, 2013.

[8] P. Suikkanen, Development and processing of low carbon bainitic steels, University of Oulu, Oulu, Finland, 2009.

[9] M. Ali, M. Eissa, H.E. Faramawy, D. Porter, J. Kömi, M.F. ElShahat, T. Mattar, J. Min. Mater. Charact. Eng. 5 (2017) 385-407.

[10] M. Ali, D.A. Porter, J.I. Kömi, M. Eissa, H. El Faramawy, M.F. El-Shahat, T.M. Mattar, Key Eng. Mater. 786 (2018) 10-22.

[11] H. Zakerinia, A. Kermanpur, A. Najafizadeh, Int. J. Iron Steel Soc. Iran 6 (2009) 14-18.

[12] F.G. Meng, J.X. Dong, M.C. Zhang, Mater. Res. Innovations 18 (2014) S4-301-S4-308.

[13] C. Wang, M. Wang, J. Shi, W. Hui, H. Dong, Scripta Mater. 58 (2008) 492-495.

[14] C.A. Apple, R.N. Caron, G. Krauss, Metall. Trans. 5 (1974) 593-599.

[15] G. Krauss, Mater. Sci. Eng. A 273-275 (1999) 40-57.

[16] V. Javaheri, T. Nyyssönen, B. Grande, D. Porter, J. Mater. Eng. Perform. 27 (2018) 2978-2992.

[17] T. Nyyssönen, M. Isakov, P. Peura, V.T. Kuokkala, Metall. Mater. Trans. A 47 (2016) 2587-2590.

[18] T. Nyyssönen, Quenching and partitioning of high-aluminum steels, Tampere University of Technology, Tampere, Finland, 2017.
[19] D.J. Dyson, J. Iron Steel Inst. 208 (1970) 469-474.

[20] S. Kumar, S.K. Nath, V. Kumar, Mater. Des. 90 (2016) $177-184$.

[21] F.G. Caballero, H. Roelofs, S. Hasler, C. Capdevila, J. Chao, J. Cornide, C. Garcia-Mateo, Mater. Sci. Technol. 28 (2012) 95-102.

[22] T. Furuhara, N. Takayama, G. Miyamoto, Mater. Sci. Forum 638-642 (2010) 3044-3049.

[23] T. Furuhara, K. Kikumoto, H. Saito, T. Sekine, T. Ogawa, S. Morito, T. Maki, ISIJ Int. 48 (2008) 1038-1045.

[24] Z.J. Luo, J.C. Shen, H. Su, Y.H. Ding, C.F. Yang, X. Zhu, J. Iron Steel Res. Int. 17 (2010) No. 11, 40-48.

[25] A. Saha Podder, H.K.D.H. Bhadeshia, Mater. Sci. Eng. A 527 (2010) 2121-2128.

[26] E. Kozeschnik, H.K.D.H. Bhadeshia, Mater. Sci. Technol. 24 (2008) 343-347.

[27] A.S. Podder, I. Lonardelli, A. Molinari, H.K.D.H. Bhadeshia, Proceedings of the Royal Society A: Mathematical, Physical and Engineering Sciences 467 (2011) 3141-3156.

[28] N. R.V. Bangaru, A.K. Sachdev, Metall. Trans. A 13 (1982) 1899-1906.

[29] N. Zhu, Q. Wu, Y. He, X. Lu, L. Li, P. Hu, Steel Res. Int. 85 (2014) 143-154.

[30] J. Hidalgo, K.O. Findley, M.J. Santofimia, Mater. Sci. Eng. A 690 (2017) 337-347.

[31] I.B. Timokhina, P.D. Hodgson, E.V. Pereloma, Metall. Mater. Trans. A 35 (2004) 2331-2341.

[32] S.C. Kennett, K.O. Findley, Adv. Mater. Res. 922 (2014) 350-355.

[33] H.F. Lan, L.X. Du, Q. Li, C.L. Qiu, J.P. Li, R.D.K. Misra, J. Alloy. Compd. 710 (2017) 702-710.

[34] X. Sun, Z. Li, Q. Yong, Z. Yang, H. Dong, Y. Weng, Sci. China Technol. Sci. 55 (2012) 1797-1805.

[35] J.A. da Cruz, J.J. Vilela, B.M. Gonzalez, D.B. Santos, Adv. Mater. Res. 922 (2014) 298-303.

[36] T. Jia, Y. Zhou, X. Jia, Z. Wang, Metall. Mater. Trans. A 48 (2017) 685-696. 